\title{
Denzin's Paradigm Shift: Revisiting Triangulation in Qualitative Research
}

\author{
Patricia Fusch \\ Walden University \\ Gene E. Fusch \\ Walden University \\ Lawrence R. Ness \\ Walden University
}

One approach to promote social change, mitigate bias, and enhance reaching data saturation is through triangulation: multiple sources of data. Triangulation adds depth to the data that are collected. In this scholarly essay, the authors discuss the continuing relevance of Denzin's approach to triangulation of data. Included is a critique of researchers who have posited other approaches to triangulation that appear to be merely a renaming of Denzin's original paradigm rather new outcomes. The intended audience is novice researchers and doctoral students who can benefit from clarity on some common misconceptions about triangulation.

Keywords: triangulation, Denzin, validity, reliability, confirmability, transferability, qualitative research, multiple data source, multiple data collection methods, mitigating bias, data saturation, social change

\section{Introduction}

Researchers often use a qualitative methodology to address social change despite the fact that most research does not study social change, per se. For example, Christensen's disruptive innovations have had a major impact on industry structures, but the social changes are, for the most part, accidental and a byproduct of the adaptions (Christensen, Baumann, Ruggles, \& Sadtler, 2006). In qualitative research, researchers accept that they cannot separate themselves from the research by bringing their personal experiences, values, and perspectives (Jackson, 1990). In other words, qualitative researchers bring their bias to the research, share their bias with the reader, and strive to mitigate their personal bias to ensure that they are correctly interpreting the other/participant. Likewise, Denzin (1978) argued that researchers bring their personal beliefs in addition to the social and political environment, which eliminates any possibility of conducting value-free research. Moreover, researchers often use a qualitative methodology to address social change, but struggle with concepts of objectivity, truth, and validity.

Social science asks the following questions: Can social science be objective? Whose truth? Whose perspective of validity? Some qualitative researchers support to the postpositivist terms or reliability and validity, whereas others use the notion of dependability, credibility, transferability, and confirmability (Lincoln \& Guba, 1985). Whether one is looking at qualitative research from a postpositivist, postmodernist, or other paradigm, it is vital to address one's position in the research and show how one will ensure the trustworthiness of the research. 
One purpose of any study is to advance theory (Imenda, 2014) through either filling a gap (Vlok, 2012) or confirming already existing evidence (Ayoko \& Pekerti, 2008). This is then accomplished by an exhaustive literature review, an empirical study to gather the evidence, and then comparing the existing body of knowledge and the conceptual framework to the study results (Chernyak-Hai \& Tzinder, 2014; Secomb \& Smith, 2011). The overall purpose of any study is to answer the research question.

One approach to mitigate bias is through triangulation: multiple sources of data (Jonsen \& Jehn, 2009). In qualitative research, triangulation adds depth to the data that is collected. This rich, indepth data supports a direct link between triangulation and data saturation (P. Fusch \& Ness, 2015). Denzin (2011) made the point that it is somewhat like looking through a crystal to perceive all the facets/viewpoints of the data. Moreover, he posited that triangulation should be reframed as crystal refraction (many points of light) to extrapolate the meaning inherent in the data, thereby mitigating one's bias. This is especially important in qualitative research when one is using multiple data collection techniques to find the meaning that participants use to frame their world (Forsey, 2010). Using strategies such as Denzin's triangulation techniques can assist with endeavors to understand the other. A researcher's cultural and experiential background contains biases, values, and ideologies that will have an influence on the interpretation of the study results (G. Fusch, 2001).

\section{Qualitative Research and Triangulation}

The application of triangulation (multiple sources of data) can enhance the reliability of the study results (Stavros \& Westberg, 2009) and enable one to saturate the data (P. Fusch \& Ness, 2015). Denzin (1989) noted that triangulation involves the employment of multiple external data collection methods concerning the same events may be enhanced by multiple external analysis methods. Triangulation is one method by which the researcher analyzes data and then presents the results to others to understand the experience of a common phenomenon (Denzin, 1989)

A qualitative researcher seeks to define and interpret unclear phenomena through nonnumerical methods of measurement that focus on meaning and insight (Kakabadse \& Steane, 2010). Exploratory research designs are conducted to clarify ambiguity and discover multiple realities (Kurt, Inman, \& Argo, 2011), as well as ideas for later research. Therefore, qualitative research techniques help researchers define and interpret the ambiguities that exploratory research designs address (Thomas \& Quinlan, 2014). Exploratory research can include interpretations of information gathered during investigations that consist of unstructured interviews, in-depth interviews, and direct observation of people, places, and phenomena (Dowlatshahi, 2010; Mansourian, 2008). Finally, exploratory research is used when the problem statement is unclear or inarticulate (Dowlatshahi, 2010).

Jackson (1990) discussed subjectivity in qualitative research and in particular cultural anthropology in her self-professed nonrandom sample of seventy anthropologists. The concept of "I am a fieldnote" or "I am the research instrument" focuses on the self in qualitative research. Researchers bring their personal milieu and values, which demonstrates subjectivity and relationships between insider/outsider and researcher/participant, further noting that some see this as strength, while others see it as a weakness (Draper \& Swift, 2011). These relationships are present in all social research, both intentionally and unintentionally (Fields \& Kafai, 2009). Jackson (1990) wrote that the personal reactions of Western anthropologists to native cultures should be of interest to researchers in addition to the study at hand. As Denzin and Lincoln (2011) stated, "qualitative 
research scholars have an obligation to change the world [to make] a positive difference. We are challenged to confront the facts of injustice... and hence open to change and transformation" (p. 511). It is what Gergen, Josselson, and Freeman (2015) referred to as the promise of qualitative inquiry, to promote social change by increasing knowledge and challenging conventions, to know with others as well as about them. It is the ability to promote social change through emancipatory action (Gergen \& Zielke, 2006; MacDonald, 2012).

To enhance social change through research, it is imperative that interpretations represent those of the participants and not of the researcher (Fields \& Kafai, 2009). Draper and Swift (2011) made two good points in their work: (a) there is no universal accepted design for data collection, and (b) the researcher plays a central, key role in the data collection phase of the study. Fields and Kafai (2009) also made these points in their discussion of ethnographic research designs. One of the most challenging parts in qualitative research is to account for the use of a personal lens, primarily because novice researchers (like students) assume that they have no bias in their data collection. However, it is important to remember that a participant's, as well as the researcher's, bias/worldview is present in all social research, both intentionally and unintentionally (Fields \& Kafai, 2009), which is why it is important to triangulate in qualitative research.

\section{Denzin's Paradigm Shift: Triangulation in Qualitative Research}

Triangulation is an important concept regarding data analysis for an empirical study. To be sure, multiple external analysis methods concerning the same events and the validity of the process can be enhanced by triangulation (G. Fusch, 2001; P. Fusch \& Fusch, 2015; P. Fusch \& Ness, 2015; Marshall \& Rossman, 2016). The importance of triangulation cannot be underestimated to ensure reliability and validity of the data and results .

External validity is represented by the ability of a study's conclusions to be transferred to other studies (Aastrup \& Halldorsson, 2013). This should be possible regardless of populations, settings, or times (Aastrup \& Halldorsson, 2013). Although external validity can be defined as transferring the findings of one study to other studies, qualitative researchers often prefer to use the concept of transferability to avoid the more positivist concept of generalizability (Lincoln \& Guba, 1985). One should leave the transferability of the findings to the reader and future researchers to determine rather than the original researcher (Marshall \& Rossman, 2016). A study has construct validity if the inferences that are made can be tied to the conceptual framework of the study (Amerson, 2011). Moreover, threats to construct validity are demonstrated by researcher bias and relying on a single measurement instrument (Amerson, 2011). Construct validity is proven by using multiple sources of data (triangulation), preserving the chain of evidence, and allowing key informants to review the data (Amerson, 2011). External validity is demonstrated by the ability of the study to be replicated, known as transferability (Roe \& Just, 2009).

What is important to remember is that the researcher mitigates bias through the data collection method that is appropriate for the study design. Hearing and understanding the perspective of others may be one of the most difficult dilemmas that face the researcher. The better a researcher is able to recognize his/her personal view of the world and to discern the presence of personal lenses, the better one is able to hear and interpret the behavior and reflections of others. For example, the use of methodological triangulation (multiple methods of data collection) will also assist in mitigating any researcher bias (Bekhet \& Zauszniewski, 2012; Gorissen, van Bruggen, \& Jochems, 2013; Horne \& Horgan, 2012: Lloyd, 2011). The ability to look at the data from multiple perspectives and consider a phenomenon in more than one way assists in mitigating the potential to see the data from just one 
view (Denzin, 1989). Using triangulation such as multiple sources of data contributes to the reliability of results (Stavros \& Westberg, 2009) and saturation of data (P. Fusch \& Ness, 2015). A case study design with at least two data collection methods (Amerson, 2011; Houghton, Casey, Shaw, \& Murphy, 2013) is one example of methodological triangulation.

Qualitative researchers have special concerns regarding validity (Cho \& Trent, 2011) and a key concept of reliability is the ability of instruments to elicit a response that remains constant over time (Golafshani, 2003). Beginning with the geometrical concept of triangulation used for centuries in ship navigation in which one draws the intersection between three known points to locate the ships position, Campbell and Fiskel (1959) — and later, Webb, Campbell, Schwartz, and Sechrest (1966)_ introduced the notion of triangulating multiple sources of data to enhance the validity of research.

\section{Four Types of Triangulation}

Denzin $(1970,1978)$ built on the notion of triangulating multiple sources of data and developed four types of triangulation that qualitative researchers can use to enhance the enhance objectivity, truth, and validity (dependability and credibility) of social research. Denzin (1989) suggested data triangulation for correlating people, time, and space; investigator triangulation for correlating the findings from multiple researchers in a study; theory triangulation for using and correlating multiple theoretical strategies; and methodological triangulation for correlating data from multiple data collection methods.

\section{Data triangulation}

Data triangulation is often confused for methodological triangulation and is most likely the most frequent mistake that students make when discussing triangulation. An abbreviated way to think about data triangulation to avoid confusion is to consider what Denzin (2009) referred to as people, time, and space. These three data points (not methods to generate data) are inter-related and ongoing. Each data point represents different data of the same event; discovering commonalities within dissimilar settings. Furthermore, the data points take place over time to observe ongoing interactions-days, weeks, months, years.

\section{Investigator triangulation}

Simply put, there is more than one investigator/researcher exploring the phenomenon. Denzin (2009) pointed out that this does not include coders, graduate students/assistants, or data analysts. Rather, the persons with the best skills should be closest to the data. Bias is mitigated by different investigators observing the same data who may not agree on its interpretation

\section{Theory triangulation}

In theory triangulation, one applies different theories and alternative theories to the data set. Particularly, one views the data through a theoretical lens and through contradictory theories. Another strategic approach is to let the raw data speak to the researcher to ascertain a new theory. The point, as noted by Denzin (2009), is to widen one's theoretical lens through a six-step process that expands one's knowledge of the known.

\section{Methodological triangulation}

Denzin $(1970,1978)$ noted that methodological triangulation can be within method or between method (also known as across method), although the generally understood type is within method, such as multiple sources of data found within one design. For example, triangulating the data from multiple data collection methods (interviews, focus groups, observations, etc.) in a qualitative case study or ethnography would be within-method triangulation, whereas triangulating the data from a 
combination of quantitative and qualitative techniques in a mixed-methods study would be betweenmethod (or across method) triangulation. The challenge is that the inherent flaws within one method are still present and can impact the data. The ideal application, Denzin (2009) stated, is betweenmethod triangulation to account for flaws and deficiencies. Between-method triangulation takes the best of both to overcome the weakness of each. In-depth understanding of the phenomenon is the goal; validity is not always enhanced.

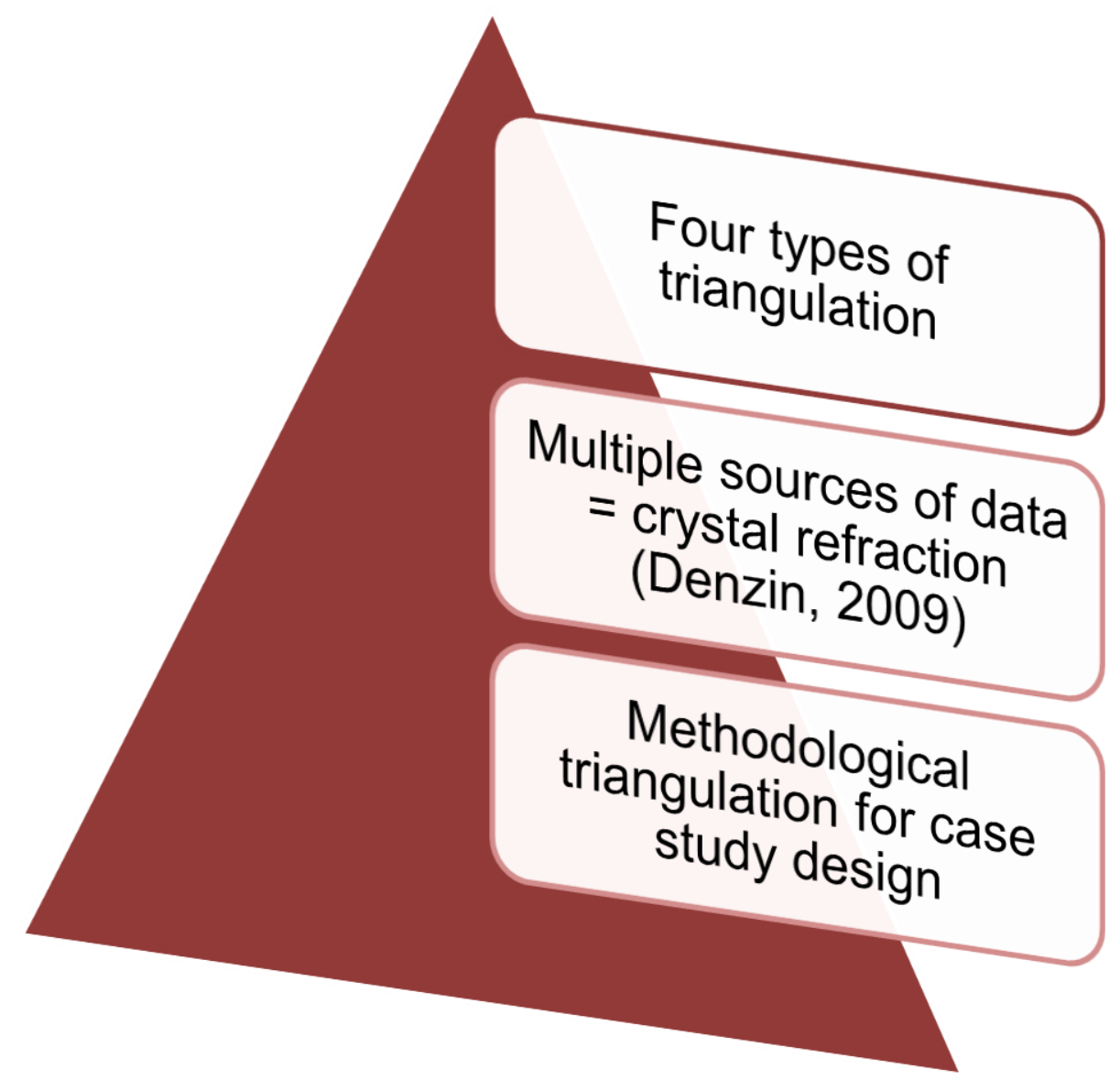

Figure 1. The four types of triangulation. Source: P. Fusch and Fusch (2013)

\section{The Importance of Triangulation}

The importance of triangulation cannot be underestimated to ensure reliability and validity of the data and results. This occurs when the data is accurate and truthful (Roe \& Just, 2009), when the inferences have a reasonable probability for actually occurring and can be tied back to the conceptual framework of the study (Roe \& Just, 2009), and by the ability of a study's conclusions to be transferred to other studies regardless of populations, settings, or times (Aastrup \& Halldorsson, 2013). It goes without saying that the study design is the most important component of the proposal-to ensure that one has the best opportunity to answer the research question (Marshall \& Rossman, 2016). 
Researcher bias/worldview is a concern whether from the standpoint of the researcher or the participant (Chenail, 2011). Chenail (2011) pointed out that the establishment and implementation of an interview protocol is important to mitigate bias, especially if the researcher is also a member of the population pool being studied. Miscommunication between participants and researchers can especially arise from misunderstandings between the two (Chenail, 2011). This is especially apparent during an interview process, during which cultural differences can manifest in communication, making the use of an interview protocol important (Amerson, 2011).

It would be impossible to remove all bias because one is a human being. Rather, one mitigates bias as best as one can (Amerson, 2011; Chenail, 2011). This is demonstrated through the use of an interview protocol, member checking, data saturation, and other strategies to mitigate the use of one personal lens during the data collection process of the study (Dibley, 2011; Torrance, 2012). Driving participants to predetermined conclusions speaks to the same concepts (Dibley, 2011). With oneself as a lens, a researcher observes and interacts with members of a culture to understand the culture, and then disseminates the researcher's interpretations to those outside the culture (P. Fusch, Ness, $\&$ Fusch, 2017).

The easiest way to differentiate between rich and thick data is to think of rich as quality and thick as quantity. Thick data is a lot of data; rich data is many-layered, intricate, detailed, nuanced, and so on. One can have a lot of thick data that is not rich; conversely, one can have rich data but not a lot of it. The challenge, if you will, is to have both.

\section{Methodological Triangulation: Mixed Methods and Blended Designs}

Methodological triangulation adds depth to the data that is collected (Manganelli et al., 2014); it is perhaps the most frequent use of triangulation by students. Its use is especially important in qualitative research designs, in which one may have multiple data collection techniques to find the meaning that participants use to frame their world (Forsey, 2010). Some of the options that are available to students for methodological triangulation include interviews, focus groups, direct observation, document analysis (Internet, Intranet, company documents, and other media), participant observation, and field notes.

\section{Mixed methods}

For mixed methods, one uses between-method triangulation. Mixed methods combines both quantitative and qualitative methods (Almajali \& Dahalin, 2011; Fielding, 2012; Hussein, 2009). A mixed-methods design has so much going for it—rich data, ability to reach data saturation easily, a comprehensive presentation of the study results (Green et al., 2015). However, along with its benefits, a mixed-methods design has a great deal of complexity in the data collection methodsmuch more than other designs (Baran, 2010; Bryman, 2008). One would have to have a great deal of knowledge regarding quantitative design as well as qualitative design (Halcomb \& Andrew, 2009), which is not typically the case with novice researchers.

Sometimes a mixed-methods strategy begins with a qualitative framework to fine-tune the questions to be asked in the quantitative phase (Baran, 2010). Regardless of the protocol, there is a distinct viewpoint where one design is dominant over the other (Baran, 2010; Bryman, 2008). As Bryman pointed out, mixed-methods research in the abstract is far different from how it is utilized in the field. Often, a mixed-methods study will begin with a qualitative method to identify and narrow down the problem. Then the quantitative method is used to answer the research question. This process can be reversed as well. Mixed methods is often described as methodological pluralism in that the use of both results in a broader perspective of the research topic (Azorin \& Cameron, 2010) 
as opposed to what are known as monomethods - qualitative or quantitative (Baran, 2010). Finally, Denzin (2012) was somewhat critical of mixed-methods research, often referring to it as naïve postpositivism, although he appears to have softened his approach.

\section{Blended design}

Blended designs combine qualitative designs, for example, an ethnographic case study, a narrative case study design, or a grounded-theory case study design. To be sure, it is not that mixed methods is inherently difficult; it is that the approach should be one that answers the research question. Blended designs and mixed methods are often confused as being the same thing; however, the differences are important. A blended design remains within the same method; a mixed-methods approach is two methods, which makes it far more complicated than a blended design. A mixedmethods design will still reflect either a quantitative framework or a qualitative one (Baran, 2010; Bryman, 2008) because a quantitative mind set is different from a qualitative mindset in so many ways (Baran, 2010). That is why mixed methodology is often discouraged for novice researchers such as students, because the thought process can be too complicated at times.

Typically, students think of blending as using a mixed-methods approach to research design; however, some students do not see that one can blend designs through using a phenomenological interview design with a case study approach. Another way to look at blending designs is to use a miniethnographic case study design (P. Fusch, Fusch, \& Ness, 2017). One has the benefit of an ethnographic approach that is bounded within a case study protocol that is more feasible for a student researcher with limited time and finances.

A blended design is often not an option mentioned to students because of its confusion with mixed methods; however, a blended design is an excellent way to obtain rich and thick data and is occasionally the answer when students are too often discouraged from conducting phenomenological studies. The challenge for students is to understand how to present the option to a reluctant committee; a phenomenological case study design can be seen from two perspectives: a case study design with phenomenological interviews or a phenomenological study that is bounded in time and space by a case study design. Reaching the point of saturating the data is much easier with case study design than with phenomenology. One further point we would add is that one can bound phenomenology with the sampling method. Another example is that the pairing of ethnography with case study design is a good choice because one can bind the ethnographic study within time and space with the case study design. Typically, ethnographers are in the field for years. If one were to pair it with case study design, one can then limit the time in the field to a timeframe that is more pragmatic for novice researchers such as students.

\section{The Postparadigm Shift}

Since Denzin initially defined the four types of triangulation in social research, there has been confusion between data triangulation and methodological triangulation. Many writers have attempted to expand on Denzin's original work by attaching new names to the same concepts that Denzin discussed (Carter, Bryant-Lukosius, DiCenso, Blythe, \& Neville, 2014; Humble, 2009; Wilson, 2014) or noting how triangulation appears to be another name for mixed-methods research. For example, Guion, Diehl, and McDonald's (2011) cooperative extension publication presents the concept of environmental triangulation. The publication was originally written as an undergraduate paper and then expanded on by others.

Upon a careful reading of the discussion, one finds that environmental triangulation is actually a renaming of the concepts found within data triangulation. For example, Guion et al. (2011) noted 
that environmental triangulation involves the use of multiple locations, settings, and other factors, which is too similar to Denzin's discussion of people, time, and space of data triangulation. Moreover, one also finds that their discussion related to data triangulation is a surface level presentation that does not correctly define what data triangulation is and is not. Much of the discussion found in Guion et al. would be better applied to methodological triangulation. This is why it is so important to return to the primary source to understand the concepts of triangulation by reading Denzin's (1970) seminal work.

\section{The Triangulation Confusion}

Frequently, we see confusion in qualitative research between data triangulation versus methodological triangulation. This appears to be an outcome of reading secondary data instead of going to the primary source. In some publications, researchers continued down the chain of secondary interpretation and an unclear representation led to an incorrect interpretation of Denzin's work. For example, Patton (2002) cited Denzin and interpreted his definition of data triangulation as "the use of a variety of sources in a study" (p. 247) and methodological triangulation as "the use of multiple methods to study a single problem or program” (p. 247). Rather than synthesizing Denzin's seminal work, Yin (2014) cited Patton's text and noted that "Patton (2002) discusses four types of triangulation in doing evaluations" and identified data triangulation as "of different sources" and methodological triangulation as "of methods" (p. 120). Patton (2002) provided a good introductory text and introduced the basic concept of triangulation, leaving the reader to look up Denzin's work for more detail. Yin is a leader in case study research; however, in this case, he elaborated on Patton's basic interpretation and stated that data triangulation "is to collect information from multiple sources but aimed at collaborating the same finding" (Yin, 2014, p. 120). Yin went on to provide examples of multiple sources one can use for data triangulation as documents, archival records, open-ended interviews, participant and direct observations, and so forth, which appears to contradict Denzin's definitions. When one looks at the concept of triangulation through a chain of interpretations rather than going to the seminal source, one can add to the confusion in the literature. When one goes back to the seminal source and looks at Denzin's (1989) definitions, one would find that "data triangulation has three subtypes: (a) time, (b) space, and (c) persons," whereas "methodological triangulation can entail within-method and between-method triangulations" (p. 237). We argue that researchers should identify the seminal (original) sources in their reading and critically read the seminal scholars' work to ensure that they are not creating more ambiguity.

\section{Triangulation, Bias, and the Student Researcher}

Denzin (2009) argued that no single method, theory, or observer can capture all that is relevant or important. Denzin (2006), however, stated that triangulation is the method in which the researcher "must learn to employ multiple external methods in the analysis of the same empirical events" (p. 13). Moreover, triangulation is the way in which one explores different levels and perspectives of the same phenomenon. It is one method by which the validity of the study results are ensured. Novice researchers should keep in mind that the triangulation of data can result in sometimes contradictory and inconsistent results; however, it is up to the researcher to make sense of them for the reader and to demonstrate the richness of the information gleaned from the data (Heale \& Forbes, 2013: O’Reilly \& Parker, 2013).

In dissertations and doctoral studies using more than one data collection method, too often, students focus on just the interview data and neglect to demonstrate methodological triangulation by discussing document analysis, direct observation, focus group interview data, or other data sources 
that are separate from the participant interview data (Denham \& Onwuegbuzie, 2013). To better understand and apply methodological triangulation (within method) in case study design, Stavros and Westberg (2009) illustrated the use of triangulation within their multiple case study research to extend knowledge of marketing theory within the sporting industry. By "corroborating data from multiple perspective to enhance the depth of understanding of a particular theme and to provide verification" within a multiple-case-study paradigm, the authors successfully "revealed a number of commonalities and some limited diversity...maximi[zing] the depth of information and increased the transferability of the findings to allow for the development of a conceptual model" (p. 307). To achieve this, Stavros and Westberg (2009) conducted semistructured interviews along with observation of key personnel, the observation with notations of managerial functions, and finally, a review and analysis of historical and secondary document artifacts across a purposive sampling of six cases.

From the viewpoint of instructors in a doctoral program, we recognize that participant storytelling can quickly become problematic due to time constraints. As a rule, participants can become quite longwinded when telling their stories and it is best to be vigilant when allowing participants to tell a story because the data can quickly morph into unintended directions. This is why follow-up and probing questions are so important: to bring the interview back on track to be able to collect data to answer the research question. The use of storytelling in data collection brings up the concept of crystallizing thorough recognizing that there are many sides from which to hear a story and understand the perspective of the participant. That being said, it is also a good idea to encourage the unfolding of serendipitous results. Storytelling is a technique that is used in qualitative research (such as narrative design) and can be utilized through the use of McCormack's lens (McCormack, 2000a, 2000b). With oneself as a lens, a researcher observes and interacts with members of a culture to understand the culture (Dibley, 2011) and one method is through storytelling. Wilson and Washington (2007) used this concept in their study to understand the experiences of African American women through their stories.

Moreover, one should not underestimate the importance of informal conversations with participants. Bernard (2011) stated that unstructured interviews are based on a clear plan constantly kept in mind, but characterized by a minimum of control over the informant's responses. It is a scheduled activity that is open ended yet follows a script. One could also apply this strategy to informal conversations that begin with, for example, a discussion about how the day is going for the participant that then morphs into conversation about challenges and the strategies the participant uses to address them. As a researcher, one can get too involved in trying to get the data needed and then miss the opportunity to foster an informal exchange that may elicit the information we need in an easier manner. Bernard (2011), as well as Elmir, Schmied, Jackson, and Wilkes (2011), cautioned against controlling the responses of the participants and missing important information that can be gained through conversations where a more nuanced approach is the better choice.

\section{Conclusion}

At the end of the day, this is what research is all about-to identify ways to make the world a better place for all. Popper (1963) made the point that new theory that survives continual testing (refutations) will demonstrate verisimilitude (closer to the truth). Sometimes as researchers, we extend the knowledge; most often we confirm or disconfirm what is already known. That being said, every study contributes to the body of knowledge regarding the framework and the topic. Socrates was known for many things, but primarily he was known for his willingness to question everything in life. This is the origin of the Socratic method in teaching: to teach through the use of pointed 
questions that stimulate critical thinking on the part of the student. As scholars, students must question everything presented to them in a reasoned and grounded manner to seek the truth about many things.

One's ability to make sense of this new world is to have a place at the table to participate in important debates about the future. This is dependent on one's understanding of the uses and misuses of the presentation of ideas through language (Popper, 1963). Moreover, it is important that as individuals and as a people that we learn from our mistakes. What is also important to have is a common understanding and language about where we go into the future as one people and one planet (Epstein, 2009). Students often become discouraged because they feel that their study needs to be an earthshaking event. That is rarely the case in doctoral studies, barring a few exceptions such as Victor Vroom, Albert Einstein, Clayton M. Christensen, and others. That being said, every study contributes to the body of knowledge regarding the framework and the topic. Students might feel that their results are minor, but we think of it like a building block-we cannot emphasize this enough: A student's study may have that one missing piece to construct a new paradigm that changes everything. Enhancing the validity of the study results through triangulation ensures that one's research is worthy of a contribution to the existing body of knowledge out there.

\section{References}

Aastrup, J., \& Halldorsson, A. (2013). Quality criteria for qualitative inquiries in logistics. European Journal of Operational Research, 144, 321-332. doi:10.1016/S0377-2217(02)00397-1

Almajali, D. A., \& Dahalin, Z. M. (2011). Applying the triangulation approach in IT-business strategic alignment and sustainable competitive advantage. IBIMA Business Review, 2011, 1-13. doi:10.5171/2011.214481

Amerson, R. (2011). Making a case for the case study method. Journal of Nursing Education, 50, 427-428. doi:10.3928.01484834-20110719-01

Ayoko, O. B., \& Pekerti, A. A. (2008). The mediating and moderating effects of conflict and communication openness on workplace trust. International Journal of Conflict Management, 19, 297-318. doi:10.1108/10444060810909275

Azorin, J. M., \& Cameron, R. (2010). The application of mixed methods in organisational research: A literature review. Electronic Journal of Business Research Methods, 8, 95-105.

Baran, M. (2010). Teaching multi-methodology research courses to doctoral students. International Journal of Multiple Research Approaches, 4, 19-27. doi:10.5172/mra.2010.4.1.019

Bekhet, A. K., \& Zauszniewski, J. A. (2012). Methodological triangulation: An approach to understanding data. Nurse Researcher, 20, 40-43.

Bernard, R. H. (2011). Research methods in anthropology: Qualitative and quantitative approaches. Thousand Oaks, CA: Sage.

Bryman, A. (2008). Of methods and methodology. Qualitative Research in Organizations and Management: An International Journal, 3, 159-168. doi:10.1108/17465640810900568

Campbell, D., \& Fiskel, D. (1959). Convergent and discriminant validation by the multitraitmultimethod matrix. Psychological Bulletin, 56, 81-105. doi:10.1037/h0046016

Carter, N., Bryant-Lukosius, D., DiCenso, A., Blythe, J., \& Neville, A., J. (2014). The use of triangulation in qualitative research. Oncology Nursing Forum, 41, 545-547. doi:10.1188/14.ONF.545.547 
Chenail, R. J. (2011). Interviewing the investigator: Strategies for addressing instrumentation and researcher bias concerns in qualitative research. The Qualitative Report, 16, 255-262. Retrieved from http://nsuworks.nova.edu/tqr/vol16/iss 1/16/

Chernyak-Hai, L., \& Tziner, A. (2014). Relationship between counterproductive work behavior, perceived justice and climate, occupational status, and leader-member exchange. Revista de Psicologia del Tabajo y de las Organiaciones, 30, 1-12. doi:10.5093/tr2014a1

Cho, J., \& Trent, A. (2011). Validity in qualitative research revisited. Qualitative Research, 6, 319340. doi:10.1177/1468794106065006

Christensen, C. M., Baumann, H., Ruggles, R., \& Sadtler, T. M. (2006, December). Disruptive innovation for social change. Harvard Business Review, 84, 94-101. Retrieved from http://hbr.org/2006/12/disruptive-innovation-for-social-change/ar/1

Denham, M. A., \& Onwuegbuzie, A. J. (2013). Beyond words: Using nonverbal communication data in research to enhance thick description and interpretation. International Journal of Qualitative Methods, 1, 670-696.

Denzin, N. K. (1970). The research act: A theoretical introduction to sociological methods. Chicago, IL: Aldine.

Denzin, N. K. (1978). The research act: A theoretical introduction to sociological methods (2nd ed.). New York, NY: McGraw Hill.

Denzin, N. (2006). Sociological methods: A sourcebook (5th ed.). New York, NY: Aldine Transaction.

Denzin, N. K. (2009). The research act: A theoretical introduction to sociological methods (3rd ed.). Englewood Cliffs, NJ: Prentice Hall.

Denzin, N. K. (2012). Triangulation 2.0. Journal of Mixed Methods Research, 6, 80-88. doi:10.1177/1558689812437186

Denzin, N. K., \& Lincoln, Y. S. (Eds.). (2011). The Sage handbook of qualitative research. Thousand Oaks, CA: Sage.

Dibley, L. (2011). Analyzing narrative data using McCormack's lenses. Nurse Researcher, 18, 13-19.

Dowlatshahi, S. (2010). A cost-benefit analysis for the design and implementation of reverse logistics systems: Case studies approach. International Journal of Production Research, 48, 13611380. doi:10.1080/00207540802552642

Draper, A. A., \& Swift, J. A. (2011). Qualitative research in nutrition and dietetics: Data collection issues. Journal of Human Nutrition \& Dietetics, 24, 3-12. doi:10.1111/j.1365277X.2010.01117.x

Elmir, R., Schmied, V., Jackson, D., \& Wilkes, L. (2011). Interviewing people about potentially sensitive topics. Nurse Researcher, 19, 12-16.

Epstein, M. (2009). Transculture: A broad way between globalism and multiculturalism. American Journal of Economics \& Sociology, 68, 327-351. doi:10.1111/j.1536-7150.2008.00626.x

Fielding, N. G. (2012). Triangulation and mixed methods designs: Data integration with new research technologies. Journal of Mixed Methods Research, 6, 124-136. doi:10.1177/1558689812437101 
Fields, D. A., \& Kafai, Y. B. (2009). A connective ethnography of peer knowledge sharing and diffusion in a tween virtual world. International Journal of Computer Supported Collaborative Learning, 4, 47-69. doi:10.1007/s11412-008-9057-1

Forsey, M. G. (2010). Ethnography as participant listening. Ethnography, 11, 558-572. doi:10.1177/1466138110372587

Fusch, G. E. (2001, December). What happens when the ROI model does not fit? Performance Improvement Quarterly, 14, 60-76. doi:10.1111/j.1937-8327.2001.tb00230.x

Fusch, P. (2015). Walden DBA classic qualitative applied case study design [Powerpoint]. Available at http://academicguides.waldenu.edu/researchcenter/osra/dba

Fusch, P. I., \& Fusch, G. E. (2015). Leadership and conflict resolution on the production line. International Journal of Applied Management and Technology, 14, 21-39. doi:10.5590/IJAMT.2015.14.1.0x

Fusch, P., \& Ness, L. (2015). Are we there yet? Data saturation in qualitative research. The Qualitative Report, 20, 1408-1416. Retrieved from http://tqr.nova.edu/wpcontent/uploads/2015/09/fusch

Fusch, P. I., Fusch, G. E., \& Ness, L. R. (2017). How to conduct a mini-ethnographic case study: A guide for novice researchers. The Qualitative Report, 22, 923-941. Retrieved from http://nsuworks.nova.edu/tqr/vol22/iss3/16

Gergen, J., Josselson, R., \& Freeman, M. (2015). The promises of qualitative inquiry. American Psychologist, 70, 1-9. doi:10.1037/a0038597

Gergen, K. J., \& Zielke, B. (2006). Theory in action. Theory \& Psychology, 16, 299-309. doi:10.1177/0959354306064278

Golafshani, N. (2003). Understanding reliability and validity in qualitative research. The Qualitative Report, 8, 597-607. Retrieved from http://nsuworks.nova.edu/tqr/vol8/iss4/6/

Gorissen, P., van Bruggen, J., \& Jochems, W. (2013). Methodological triangulation of the students' use of recorded lectures. International Journal of Learning Technology, 8, 20-40. doi:10.1504/IJLT.2013.052825

Green, C., Duan, N., Gibbons, R., Hoagwood, K., Palinkas, L., \& Wisdom, J. (2015). Approaches to mixed methods dissemination and implementation research: Methods, strengths, caveats, and opportunities. Administration and Policy in Mental Health and Mental Health Services Research, 42, 508-523. doi:10.1007/s10488-014-0552-6

Guion, L. A., Diehl, D. C., \& McDonald, D. (2011). Triangulation: Establishing the validity of qualitative studies. Gainesville, FL: University of Florida Cooperative Extension Service, Institute of Food and Agricultural Sciences, EDIS.

Halcomb, E., \& Andrew, S. (2009). Practical considerations for higher degree research students undertaking mixed methods projects. International Journal of Multiple Research Approaches, $3,153-162$.

Heale, R., \& Forbes, D. (2013). Understanding triangulation in research. Evidence Based Nursing, 16, 98. doi:10.1136/eb-2013-101494

Horne, C., \& Horgan J. (2012). Methodological triangulation in the analysis of terrorist networks. Studies in Conflict \& Terrorism, 35, 182-192. doi:10.1080/1057610x.2012.639064 
Houghton, C., Casey, D., Shaw, D., \& Murphy, K. (2013). Rigour in qualitative case-study research. Nurse Researcher, 20, 12-17. doi:10.7748/nr2013.03.20.4.12.e326

Humble, A. M. (2009). Technique triangulation for validation in directed content analysis. International Institute for Qualitative Methodology, 8, 34-51. Retrieved from http://ejournals.library.ualberta.ca/index.php/IJQM/article/viewFile/1480/5586

Hussein, A. (2009). The use of triangulation in social sciences research: Can qualitative and quantitative methods be combined? Journal of Comparative Social Work, 1, 1-12.

Imenda, S. (2014). Is there a conceptual difference between theoretical and conceptual frameworks? Journal of Social Sciences, 38, 185-195.

Jackson, J. E. (1990). I am a fieldnote: Fieldnotes as a symbol of professional identity. In R. Sanjek (Ed.), Fieldnotes: The making of anthropology (pp. 3-33). Ithaca, NY: Cornell University Press.

Jonsen, K., \& Jehn, K. A. (2009). Using triangulation to validate themes in qualitative studies. Qualitative Research in Organizations and Management: An International Journal, 4, 123150. doi:10.1108/17465640910978391

Kakabadse, N. K., \& Steane, P. (2010). Meaning and interpretation: Insights and discourse. Journal of Management History, 16, 346-366. doi:10.1108/17511341011051243

Kurt, D., Inman, J. J., \& Argo, J. J. (2011). The influence of friends in consumer spending: The role of agency-community orientation, and self-monitoring. Journal of Marketing Research, 48, 741-754. doi:10.1509/jmkr.48.4.741

Lincoln, Y. S., \& Guba, E. G. (1985). Naturalistic inquiry. Newbury Park, CA: Sage.

Lloyd, S. (2011). Triangulation research to inform corporate reputation and practice. Corporate Reputation Review, 14, 221-223. doi:10.1057/crr.2011.16

MacDonald, C. (2012). Understanding participatory action research: A qualitative research methodology option. Canadian Journal of Action Research, 13, 34-50.

Manganelli, J., Threatt, A., Brooks, J., Healy, S., Merino, J., Yanik, P., \& Green, K. (2014). Confirming, classifying, and prioritizing needed over-the-bed table improvements via methodological triangulation. Health Environments Research \& Design Journal, 8, 94-114.

Mansourian, Y. (2008). Exploratory nature of, and uncertainty tolerance in, qualitative research. New Library World, 109, 273-286. doi:10.1108/03074800810873614

Marshall, C., \& Rossman, G. (2016). Designing qualitative research (6th ed.). Thousand Oaks, CA: Sage.

McCormack, C. (2000a). From interview transcript to interpretive story: Part 1: Viewing the transcript through multiple lenses. Field Methods, 12, 282-297. doi:10.1177/1525822X0001200402

McCormack, C. (2000b). From interview transcript to interpretive story: Part 2: Developing an interpretive story. Field Methods, 12, 298-315. doi:10.1177/1525822X0001200403

O'Reilly, M., \& Parker, N. (2013). Unsatisfactory saturation: A critical exploration of the notion of saturated sample sizes in qualitative research. Qualitative Research Journal, 13, 190-197. doi:10.1177/1468794112446106

Patton, M. Q. (2002). Qualitative research and evaluation methods, (3rd ed.). Thousand Oaks, CA: Sage. 
Popper, K. R. (1963). Conjectures and refutations: The growth of scientific knowledge. New York, NY: Harper \& Row.

Roe, B. E., \& Just, D. R. (2009). Internal and external validity in economics research: Tradeoffs between experiments, field experiments, natural experiments, and field data. American Journal of Agricultural Economics, 91, 1266-1271. doi:10.1111/j.14678276.2009.01295.x.

Secomb, J. M., \& Smith, C. (2011). A mixed method pilot study: The researchers' experiences. Contemporary Nurse: A Journal for the Australian Nursing Profession, 39, 31-35.

Stavros, C., \& Westberg, K. (2009). Using triangulation and multiple case studies to advance relationship marketing theory. Qualitative Market Research, 12, 307-320. doi:10.1108/13522750910963827

Thomas, R., \& Quinlan, E. (2014). Teaching and learning focus group facilitation: An encounter with experiential learning in a graduate sociology classroom. Transformative Dialogues: Teaching \& Learning Journal, 7, 1-15.

Torrance, H. (2012). Triangulation, respondent validation, and democratic participation in mixed methods research. Journal of Mixed Methods Research, 6, 111-123. doi:10.1177/1558689812437185

Vlok, A. (2012). A leadership competency profile for innovation leaders in a science-based research and innovation organization in South Africa. Procedia-Social and Behavioral Sciences, 41, 209-226. doi:10.1016/j.sbspro.2012.04.025

Webb, E. J., Campbell, D. T., Schwartz, R. D., \& Sechrest, L. (1966). Unobtrusive measures: Nonreactive research in the social sciences. Chicago, IL: Rand McNally.

Wilson, V. (2014). Research methods: Triangulation. Evidence Based Library and Information Practice, 9, 74-75.

Wilson, D., \& Washington, G. (2007). Retooling phenomenology: Relevant methods for conducting research with African American women. Journal of Theory Construction and Testing, 11, 6366.

Yin, R. K. (2013, July 10). Validity and generalization in future case study evaluations. Evaluation, 19, 312-332. doi:10.1177/1356389013497081

Yin, R. K. (2014). Case study research: Design and methods (5th ed.). Thousand Oaks, CA: Sage.

The Journal of Social Change, sponsored by Walden University, welcomes manuscripts focusing on interdisciplinary research in social change that improves the human condition and moves people, groups, organizations, cultures, and society toward a more positive future.

Walden University Publishing: http://www.publishing.waldenu.edu 